Journal of the Brazilian Society of Mechanical Sciences and EngineeringVolume 40, Issue 6, 1 June 2018, Article number 289

\title{
Study of internal flow of a bipropellant swirl injector of a rocket engine(Article)
}

- $\quad$ Rivas, J.R.R. ${ }^{a}$ Email Author,

- Pimenta, A.P. ${ }^{\text {b}}$ Email Author,

- Salcedo, S.G. ${ }^{\mathrm{b}}$,

- Rivas, G.A.R. ${ }^{c}$ Email Author,

- $\quad$ Suazo, M.C.G. ${ }^{\mathrm{d}}$ Email Author

- View Correspondence (jump link)

- $\quad$ aDepartamento de Ingeniería Mecatrónica, Universidad Peruana de Ciencias Aplicadas (UPC), Campus Monterrico, Prolongación Av. Primavera 2390, Surco, Lima, Peru

- $\quad{ }^{b}$ Divisão de Engenharia Aeronáutica, Instituto Tecnológico de Aeronáutica (ITA), Comando Geral de Tecnologia Aeroespacial - Praça Marechal Eduardo Gomes 50, Vila Das Acacias, São José Dos Campos, São Paulo, CEP 12228900, Brazil

- $\quad$ Curso: Engenharia de Energia, Universidade Federal de Integração Latinoamericana (UNILA), Av. Tancredo Neves 3838 - Porto Belo, Foz do Iguaçu, CEP 85867-970, Brazil

$\underline{\text { View additional affiliations }}$

\begin{abstract}
View references (22)
This work presents the study of the behavior of the internal flow in a swirl bipropellant injector, which is composed of an open-end (without nozzle) and a closed injector (with nozzle). In this way, each of these injectors has a characteristic behavior with respect to velocity distribution, pressure, and other main parameters. In this study, three methods are used, which are: experimental, numerical, and analytical. For the numerical simulation was used a three-dimensional structured mesh, capable of holding three important areas: the oxidizer swirl chamber (closed swirl injector), the fuel swirl chamber (open-end swirl injector), and the area designed for the spray zone, which will include the phenomena caused by the interaction of the flow of the oxidant and the fuel within the bipropellant injector. The simulation was carried out through the commercial code CFD fluent in permanent regime, using the RNG k-epsilon turbulent model and the volume of fluid multiphase model to locate the liquid-gas interface. In addition, experimental data and a mathematical model developed based on theories of Abramovich and Kliachko are also presented. (C) 2018, The Brazilian Society of Mechanical Sciences and Engineering.
\end{abstract}




\section{Author keywords}

Abramovich theoryBipropellant swirl injectorClosed swirl injectorKlia Kliachko theoryOpen-end swirl injector

\section{Indexed keywords}

Engineering Fuel injectionNozzlesNumerical methodsPhase interfacesRocket controlled terms: enginesRockets

Engineering Abramovich theoryCommercial codesKlia Kliachko theoryMain uncontrolled terms parametersMultiphase modelStructured meshSwirl

Engineering main heading: injectorsVolume of fluids

- ISSN: 16785878

- Source Type: Journal

- Original language: English

- DOI: $10.1007 / \mathrm{s} 40430-018-1205-6$

- Document Type: Article

- Publisher: Springer Verlag 